\title{
Influence of the Strength of the Filling Body on the Surface
}

\section{Subsidence and Deformation}

\author{
Pengfei Yang ${ }^{1, a^{*}}$, Yukai Wang ${ }^{1, b}$, Xiangxiang Yang ${ }^{1, c}$ \\ ${ }^{1}$ Faculty of Resource and Safety Engineering, China University of Mining and Technology (Beijing), \\ Beijing 100083, China



Key Words: strength of filling body; numerical simulation; vertical stress; vertical displacement; horizontal displacement

\begin{abstract}
In order to research the Influence of the strength of the filling body on the surface subsidence and deformation, with the 10203 working face of Xinyang Mine as the background, based on the numerical simulation software of FLAC3D, when the filling rate was $90 \%$, the Influence of the strength of the filling body on the surface subsidence and deformation was researched under conditions of different strength of filling body(the strength of the filling body was $0.05,0.1,0.15,0.2,0.3,0.4$ times of the coal body). Research has shown that with the increase of the strength of the filling body, the vertical stress of the roadway roof increased; the maximum vertical displacement and horizontal displacement decreased. When the strength of the filling body was more than 0.2 times of the coal body, the Influence of the strength of the filling body on the surface subsidence and deformation was stabilizing. At this time, the vertical stress of the roadway roof was $0.3615 \mathrm{MPa}$; the maximum vertical displacement was $68 \mathrm{~mm}$, the maximum horizontal displacement was $8.5 \mathrm{~mm}$; which meet the requirement of the national protection of first class.
\end{abstract}

\section{Introduction}

Along with the massive exploitation of coal resources, "Three under" (under buildings, railways, water) coal stock problem is becoming increasingly prominent and seriously affects the sustainable development of coal industry in our country[1,2]. Filling mining, as a new type of coal mining technology provides a more ideal way for the safe and efficient mining of coal under buildings, reducing environmental pollution and improving resource recovery rate[3,4].

During coal mining and filling process, the strength of filling body are the key factors influencing the surface movement deformation. If strength of filling body is too small, the surface of the vertical deformation and horizontal deformation are larger, the normal production in the process of mining will be affected. Strength of filling body is too large, it will bring more challenges to the preparation of filling material and greatly increases the cost of filling at the same time. With the wide application of filling mining technology, many scholars began to strengthen researches on filling materials, equipment, process and method research [5-7].Many scholars at home and abroad did some researches on the mechanical properties and damage characteristics of filling material, and obtained some research results of guiding significance. Fall worked on the filling of strength property, the damage characteristics [8,9]. Jun-ming $\mathrm{Xu}$ studied the compaction deformation law of waste rock - fly ash in the process of filling materials, and obtained optimal formula of the filling body of coal gangue and fly ash. However, researches on the influence of the strength of filling body on surface movement deformation are less. Based on the site conditions 
of10203 working face of filling in mining area ten in Xinyang colliery, I use the FLAC3D numerical simulation to explore the influence of the strength of filling body on surface movement deformation, in order to provide effective guide on the coal mining under buildings.

\section{The Establishment of the Numerical Simulation Model}

Mining Geological Situation. This time 10203 comprehensive mechanized filling mining working face in mining area ten in Xinyang colliery is selected as a prototype for simulation, coal seam of 2 \#, the average depth of $200 \mathrm{~m}$, coal seam thickness of $2.33 \mathrm{~m}$, dip Angle of coal seam $3{ }^{\circ}$, complicated geological conditions. From the 1 \# coal seam in $8.03 \mathrm{~m}$. Working face $100 \mathrm{~m}$ long, advancing about $405 \mathrm{~m}$ length, transportation lane $4.2 \mathrm{~m}$ wide, material lane $3.5 \mathrm{~m}$ wide. Direct roof of coal seam is black mudstone with the average thickness of $1.65 \mathrm{~m}$; the old roof is sandstone, 3.11 $\mathrm{m}$ thick; the direct bottom for mudstone, $3.46 \mathrm{~m}$ thick.

The Establishment of the Numerical Model. Considering the influence of boundary conditions on the simulation and the need to simplify the calculation process, according to the practical geological condition of working face, the numerical simulation model of $340 \times 300 \times 207$ is established. Along the $\mathrm{x}$, y direction, respectively is $340 \mathrm{~m}, 300 \mathrm{~m}$; the length of working face advancing along the $\mathrm{x}$ direction is $140 \mathrm{~m}$, the length of working face $100 \mathrm{~m}$. The model height along $\mathrm{z}$ direction calculated according to the thickness of coal strata, total height is $207 \mathrm{~m}$. Grid adopts unequal division to carry out unit processing on the topsoil and coal rock layer near the surface.

\section{The Analysis of Numerical Simulation Results}

The Influence of the Strength of Filling Body on Vertical Stress. Figure 1 (a) (b) (c) (d) (e) (f) are roof vertical stress when filling body strength is respectively $0.05,0.1,0.15,0.2,0.3,0.4$ times the strength of coal. 


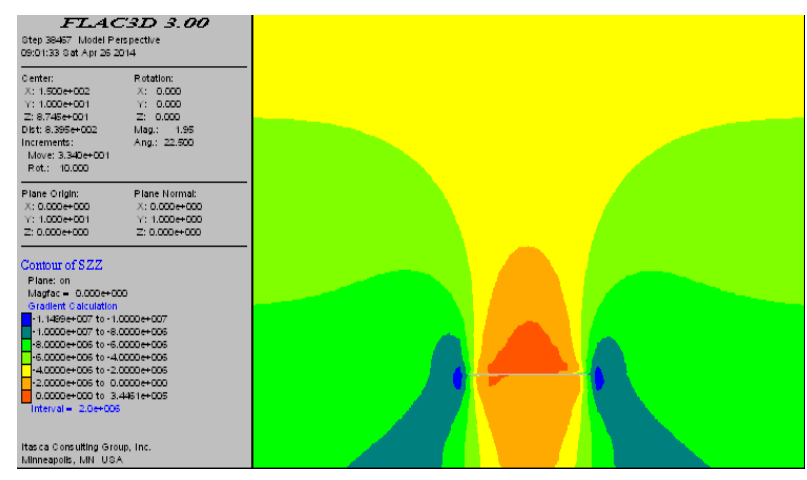

(a) 0.05 times the vertical stress

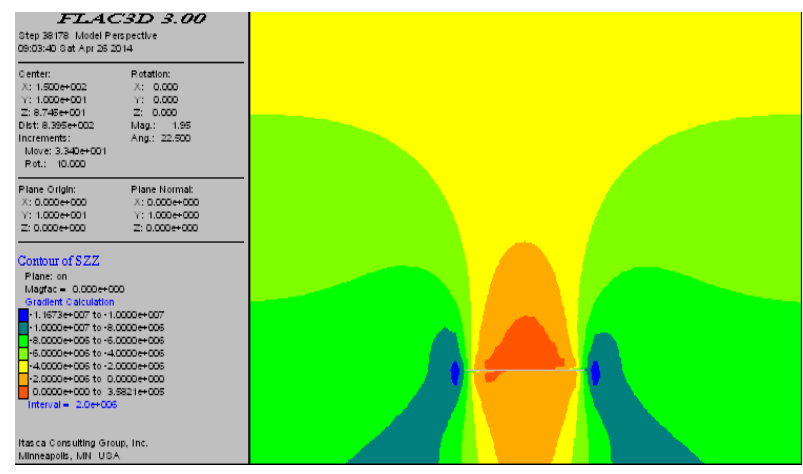

(c) 0.15 times the vertical stress

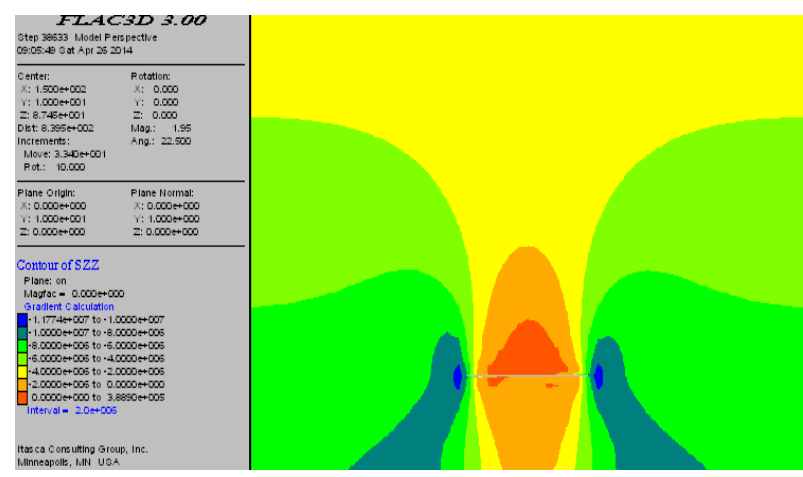

(e) 0.3 times the vertical stress

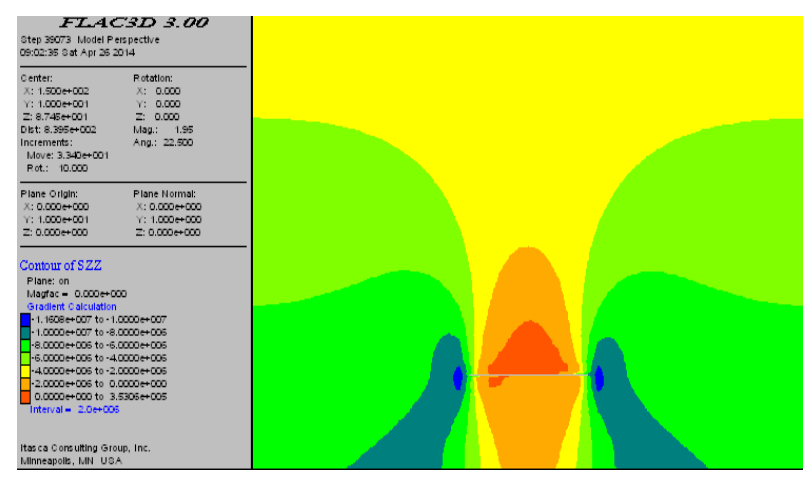

(b) 0.1 times the vertical stress

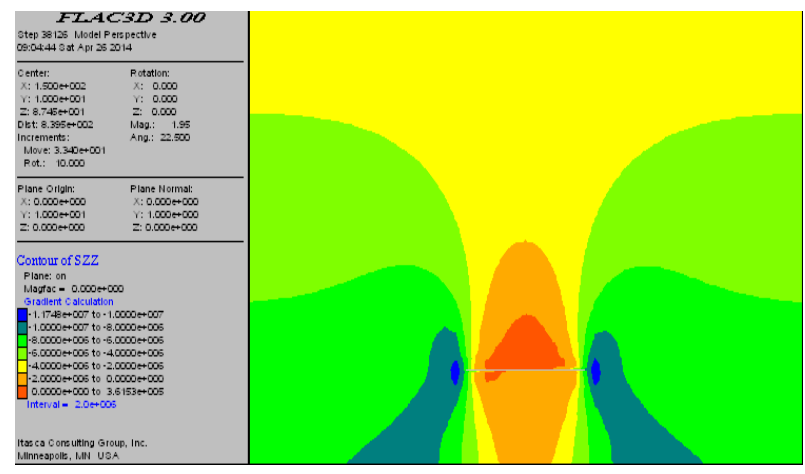

(d) 0.2 times the vertical stress

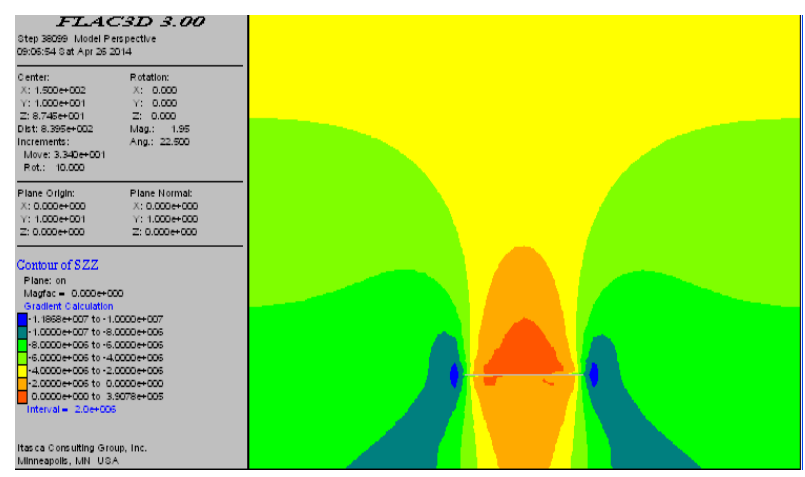

(f) 0.4 times the vertical stress

Fig.1 Different filling body strength corresponding roof vertical stress

As shown in vertical stress diagram, when the strength of filling body is 0.05 times ,the maximum strength of vertical stress is $0.3445 \mathrm{MPa}$; when the strength of filling body is 0.1 times ,the maximum strength of vertical stress is $0.3531 \mathrm{MPa}$; when the strength of filling body is 0.15 times , the maximum strength of vertical stress is $0.3582 \mathrm{MPa}$; when the strength of filling body is 0.2 times ,the maximum strength of vertical stress is $0.3615 \mathrm{MPa}$; when the strength of filling body is 0.3 times, the maximum strength of vertical stress is $0.3889 \mathrm{MPa}$; when the strength of filling body is 0.4 times ,the maximum strength of vertical stress is $0.3908 \mathrm{MPa}$. Based on the above data, with the increase of strength of filling body, the vertical stress of roadway roof increases gradually. When filling body strength increases, the pressure of filling body on the level of the two sides of roadway is gradually increasing at the same time; Horizontal stress changes of the both roadway make the change of the stress state of roadway roof, so that the vertical stress of the roadway roof increases.

The Influence of Strength of Filling Body on Vertical Displacement. Figure 2 (a) (b) (c) (d) 
(e) (f) are vertical displacement when filling body strength is respectively $0.05,0.1,0.15,0.2,0.3,0.4$ times the strength of coal.

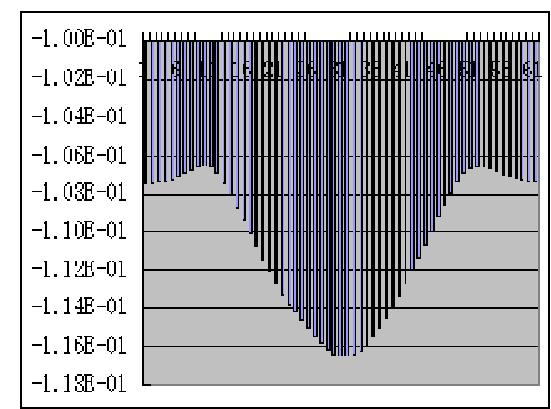

(a) Vertical displacement of 0.05 times

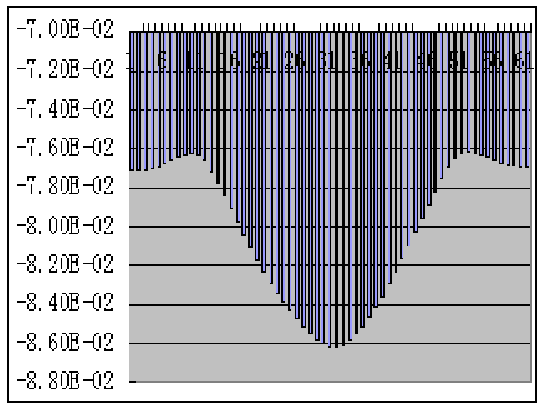

(c) Vertical displacement of 0.15 times

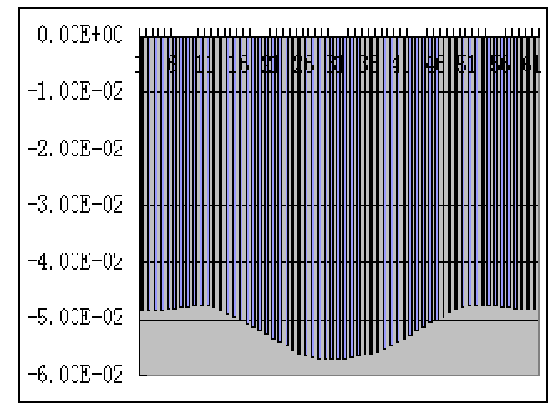

(e) Vertical displacement of 0.3 times

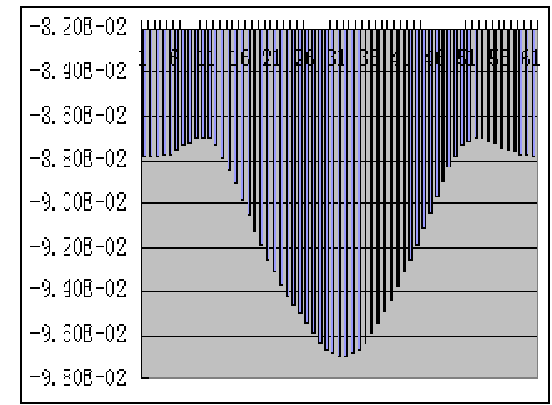

(b) Vertical displacement of 0.1 times

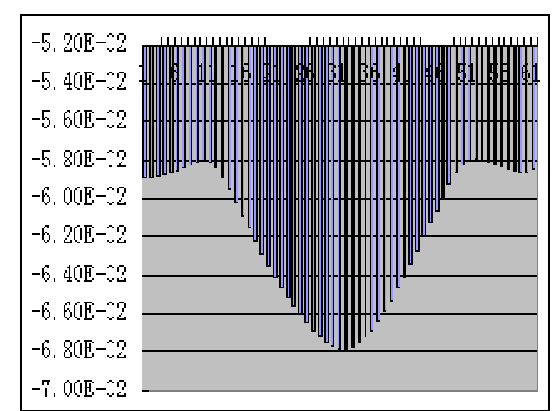

(d) Vertical displacement of 02 times

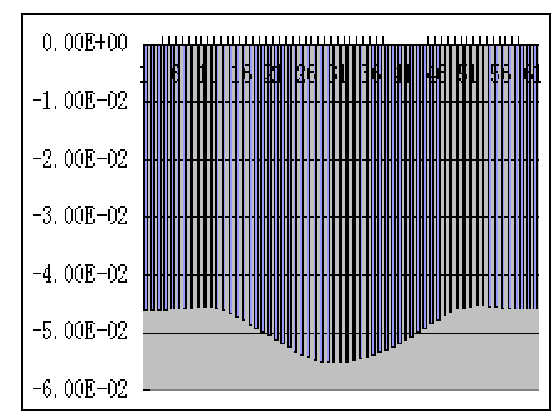

(f) Vertical displacement of 0.4 times

Fig.2 Vertical displacement of different filling body strength

According to the experimental data, when the strength of filling body is $0.05,0.1,0.15,0.2$, 0.3, 0.4 times, the maximum ground subsidence value is $117 \mathrm{~mm}, 97 \mathrm{~mm}, 86 \mathrm{~mm}, 68 \mathrm{~mm}, 57 \mathrm{~mm}$, $55 \mathrm{~mm}$. The image of maximum vertical displacement change with strength of filling body can be concluded based on these data, as shown in figure 3.

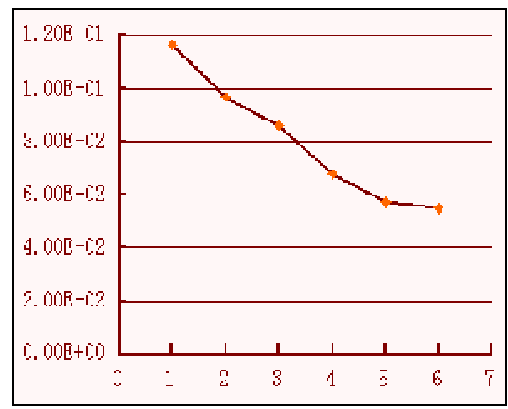

Fig.3 The maximum vertical displacement change

The horizontal axis 1 to 6show the maximum vertical displacement value when filling body strength is $0.05,0.1,0.15,0.2,0.3,0.4$ times of coal mass strength. According to figure 2 , with the increase of strength of filling body, vertical displacement decreases, and when the strength of filling 
body is greater than or equal to 0.2 times of coal mass strength ,the image goes towards flattening; That means when the filling body strength is greater than 0.2 times, the influence of strength of filling body on the surface vertical deformation becomes stable, in the influence of the maximum ground subsidence value is $68 \mathrm{~mm}$, which accords with national level of protection standard.

The Influence of Strength of Filling Body on the Horizontal Displacement. Figure 4 (a) (b) (c) (d) (e) (f) are horizontal displacement when filling body strength is respectively $0.05,0.1,0.15,0.2,0.3,0.4$ times the strength of coal.

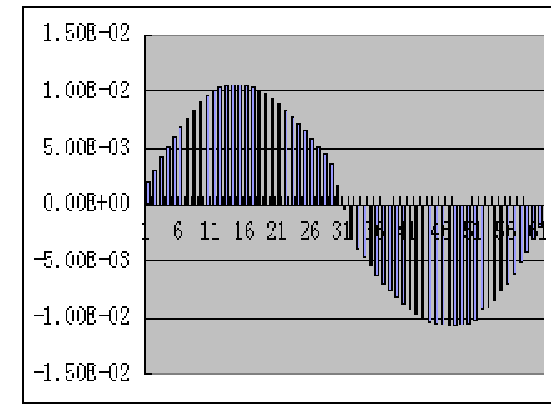

(a) Horizontal displacement of 0.05 times

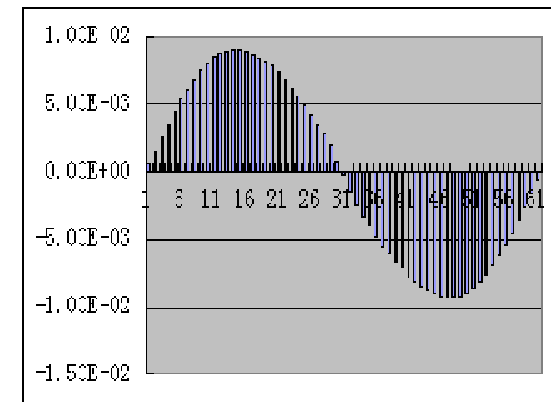

(c) Horizontal displacement of 0.15 times

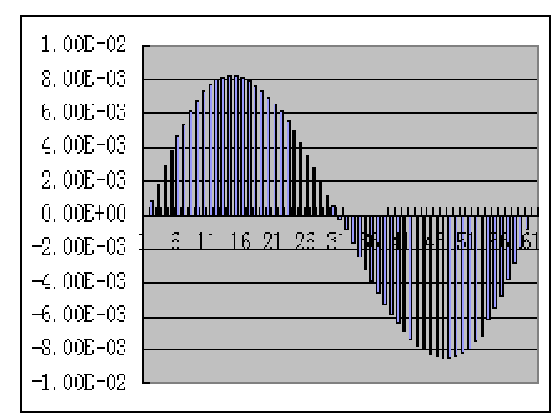

(e) Horizontal displacement of 0.3 times

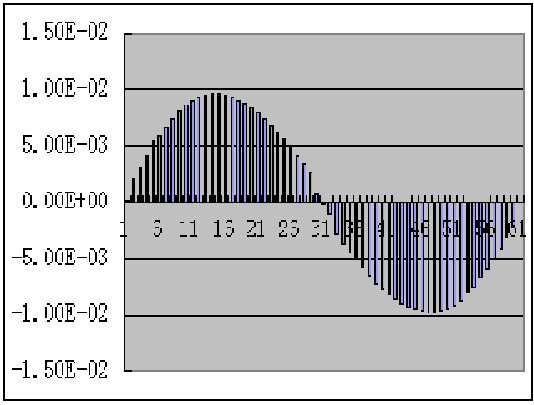

(b) Horizontal displacement of 0.1 times

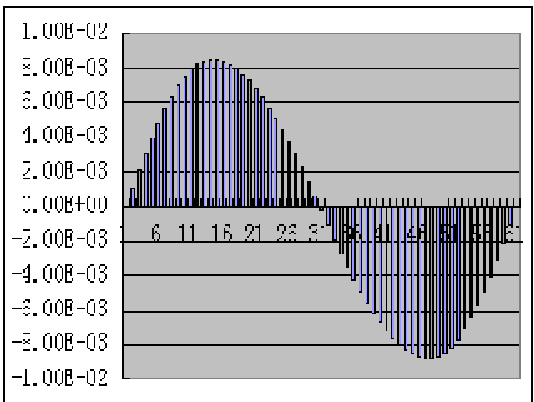

(d) Horizontal displacement of 0.2 times

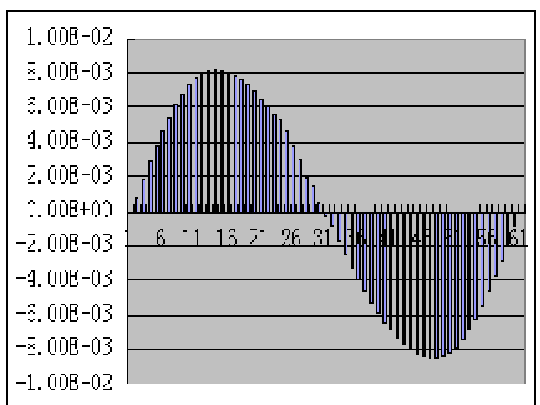

(f) Horizontal displacement of 0.4 times

Fig.4 Horizontal displacement of different filling body strength

Based on the experimental data, when the strength of filling body is $0.05,0.1,0.15,0.2,0.3$, 0.4 times, the maximum value of ground surface horizontal displacement is $10.6 \mathrm{~mm}, 9.6 \mathrm{~mm}, 9.0$ $\mathrm{mm}, 8.5 \mathrm{~mm}, 8.2 \mathrm{~mm}, 8.6 \mathrm{~mm}$. The image of maximum horizontal displacement change with strength of filling body can be concluded based on these data, as shown in figure 5 . 


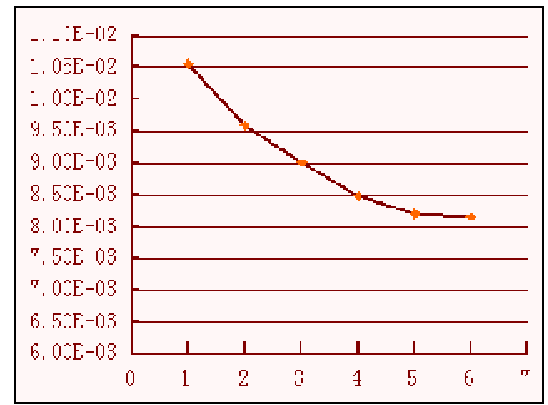

Fig.5 The maximum horizontal displacement change

The horizontal axis 1 to 6show the maximum horizontal displacement value when filling body strength is $0.05,0.1,0.15,0.2,0.3,0.4$ times of coal mass strength. According to figure 4 , with the increase of strength of filling body, horizontal displacement decreases, and when the strength of filling body is greater than or equal to 0.2 times of coal mass strength ,the image goes towards flattening; That means when the filling body strength is greater than 0.2 times, the influence of strength of filling body on the ground surface horizontal displacement becomes stable, the maximum ground surface horizontal displacement value is $8.5 \mathrm{~mm}$, which accords with national level of protection standard.

To sum up, the maximum vertical displacement and the maximum horizontal displacement increases at the same change trend with strength of filling body. The greater the strength of filling body, the smaller the vertical deformation and horizontal deformation on the surface; but the greater of the strength of filling body means the higher of the cost, when the surface controlling meets the national standard, less cost means more conducive to the development of the enterprise. On the other hand, strength of filling body is over small, the surface vertical deformation and horizontal deformation will be bigger, and packing bracket needs forward movement in time in the process of production, so that the subsequent production goes smoothly which also requires the strength of filling body with strong self-reliance. Comprehensively considered, when the strength of filling body is 0.2 times of coal mass strength as the best, the maximum ground subsidence value is $68 \mathrm{~mm}$, maximum ground surface level is $8.5 \mathrm{~mm}$, which meets the requirements of the protection, the requirements of the protection of the building and the production requirements, at the same time makes the lowest cost of production.

\section{Conclusions}

This paper combines coal mine geological conditions and mining situation of 2 \# coal seam in Xinyang colliery of Fenxi Mining Group, and does research on the effects of the strength of filling body on surface subsidence after the high concentration of cemented filling mining. The research results show that high concentration of cemented filling mining method is feasibility. The following conclusion obtain from a series of analysis and research:

(1) High concentration of cemented filling mining is suitable for higher requirements on the surface deformation of the coal mining under buildings, not only can achieve effective utilization of gangue, but also can exploit coal resources which the traditional mining methods can't, thus it improves the utilization rate of resources and achieve great economic benefits and social benefits.

(2) According to the calculation of FLAC3D numerical simulation, it is concluded that the strength of filling body is 0.2 times of coal mass strength as the best, at this time can not only make the surface subsidence controlled within the destruction range of Class 1, but also meet the requirement of safety in production, and reduce the production cost by saving material consumption. 
(3) Based on actual conditions in coal mines of Xinyang colliery, after filling the mined-out area, the expected analysis of surface movement deformation is carried out which shows the maximum horizontal displacement of mining area surface is $8.5 \mathrm{~mm}$ and maximum subsidence value is $68 \mathrm{~mm}$.

\section{References}

[1] Kexi Pan, Pu Jin, Tao Xiang, Management World, 2002, 12: 77-88. In Chinese.

[2] Baogui Yang. Coal high concentration of cemented backfill mining technology [M].Coal Industry Press, 2015, 4. In Chinese.

[3] Baogui Yang, Yanghao Peng, Yang Li, Metal Mine, 2014, 12: 169-174. In Chinese.

[4] Jixiong Zhang, Xiexing Miao, Guangli Guo, Journal of Mining \& Safety Engineering, 2009, 26(4): 395-401. In Chinese.

[5] Qingliang Chang, Huaqiang Zhou, Jianbiao Bai, Journal of Mining \& Safety Engineering, 2011, 28(2): 279 -282. In Chinese.

[6] Guangming Feng, Chundong Sun, Chengzhen Wang, Journal of China Coal Society, 2010, 35(12):1963-1968. In Chinese.

[7] Baogui Yang, Juntao Wang, Yongliang Li, Coal Science and Technology, 2013, 41 (08):28-32. In Chinese.

[8] Fall M, Benzaazoua M, Cement and Concrete Research,2005,35(2): 301-314.

[9] Fall M, BenzaazouaM, Saae G. Tunnelling and Underground Space Technology,2008,23(1): 80-90. 